\title{
EDITORIAL Reducing the burden of spine fusion
}

\author{
Marcus D. Mazur, MD, and Andrew T. Dailey, MD \\ Department of Neurosurgery, Clinical Neurosciences Center, University of Utah, Salt Lake City, Utah
}

$\mathrm{F}$ OR many patients, the experience of undergoing a lumbar fusion operation carries the burden of managing postoperative pain, enduring the risk of perioperative complications, and experiencing the inconvenience of a prolonged recovery in a hospital setting, among other potential damages. Such burdens of lumbar fusion have led many patients to seek alternative treatments (for example, chiropractic treatment, spinal injections, and platelet-rich plasma therapy) and many clinicians to dissuade patients from seeking surgical options.

Nevertheless, fusion of the lumbar spine is an effective treatment for a number of degenerative, traumatic, inflammatory, and oncological pathologies. ${ }^{1,2}$ Two strategies aimed to reduce the burden of lumbar fusion are the refinement of minimally invasive surgical (MIS) techniques and the implementation of principles of enhanced recovery after surgery (ERAS). ${ }^{3-7}$

In this article, the group from Miami describe their method of implementing concepts of MIS and ERAS to minimize surgical and perioperative morbidity in patients undergoing transforaminal lumbar interbody fusion (TLIF). ${ }^{4}$ Analyzing their experience with the first 100 patients undergoing an awake endoscopic MIS-TLIF, the authors describe the feasibility of performing lumbar fusion using conscious sedation, local analgesia, and minimal soft-tissue disruption.

Successful completion of awake MIS-TLIF occurred in most patients, with only four cases requiring conversion to general endotracheal anesthesia. The average hospital length of stay was 1.4 days. As expected, most complications occurred within the first 50 cases, and complications decreased in frequency as the technique and protocols were refined. Clinical improvement in the Oswestry Disability Index was observed at 1 year. Overall, the authors are to be congratulated for successfully implementing a safe, reproducible protocol for performing awake MISTLIF with the goal of low perioperative morbidity and faster recovery.

This article describes a proof of principle for awake
MIS-TLIF, but there are some remaining questions. The lack of a control group prevents the authors from demonstrating a true benefit of their technique over a traditional TLIF operation. Does performing a lumbar fusion using conscious sedation decrease postoperative pain? Can a mesh expandable interbody cage inserted endoscopically create sufficient segmental lordosis or indirect decompression? Can the same fusion rate as for open TLIF be achieved? Are the results durable over time? Which patient populations should be considered safe for an awake MIS-TLIF? These are among the remaining questions that should be addressed before awake MIS-TLIF becomes widely adopted.

The principles of MIS and ERAS are increasing in popularity and confer a number of potential advantages for patients. The proposed technique offers a glimpse into the future of fusion techniques for the lumbar spine. The members of this group from Miami are among those leading the advancement of spine surgery in these areas. ${ }^{4}$

https://thejns.org/doi/abs/10.3171/2019.1.FOCUS1945

\section{Reference}

1. Abdu WA, Sacks OA, Tosteson ANA, Zhao W, Tosteson TD, Morgan TS, et al: Long-term results of surgery compared with nonoperative treatment for lumbar degenerative spondylolisthesis in the Spine Patient Outcomes Research Trial (SPORT). Spine (Phila Pa 1976) 43:1619-1630, 2018

2. Ghogawala Z, Dziura J, Butler WE, Dai F, Terrin N, Magge $\mathrm{SN}$, et al: Laminectomy plus fusion versus laminectomy alone for lumbar spondylolisthesis. N Engl J Med 374:14241434,2016

3. Grasu RM, Cata JP, Dang AQ, Tatsui CE, Rhines LD, Hagan KB, et al: Implementation of an Enhanced Recovery After Spine Surgery program at a large cancer center: a preliminary analysis. J Neurosurg Spine 29:588-598, 2018

4. Kolcun JPG, Brusko GD, Basil GW, Epstein R, Wang MY: Endoscopic transforaminal lumbar interbody fusion without general anesthesia: operative and clinical outcomes in 100 consecutive patients with a minimum 1-year follow-up. Neurosurg Focus 46(4):E14, 2019 
5. Phan K, Rao PJ, Kam AC, Mobbs RJ: Minimally invasive versus open transforaminal lumbar interbody fusion for treatment of degenerative lumbar disease: systematic review and meta-analysis. Eur Spine 24:1017-1030, 2015

6. Seng C, Siddiqui MA, Wong KP, Zhang K, Yeo W, Tan SB, et al: Five-year outcomes of minimally invasive versus open transforaminal lumbar interbody fusion: a matched-pair comparison study. Spine (Phila Pa 1976) 38:2049-2055, 2013

7. Wainwright TW, Immins T, Middleton RG: Enhanced recovery after surgery (ERAS) and its applicability for major spine surgery. Best Prac Res Clin Anaesthesiol 30:91-102, 2016

\section{Disclosures}

Dr. Dailey reports being a consultant to Zimmer Biomet and receiving an honorarium from AO North America. He also oversees a non-study-related clinical or research effort that receives support from K2M.

\section{Correspondence}

Andrew T. Dailey: andrew.dailey@hsc.utah.edu.

\section{INCLUDE WHEN CITING}

DOI: 10.3171/2019.1.FOCUS1945. 